ORIGINAL PROF-2250

\title{
LOWER SEGMENT CESAREAN SECTION (LSCS);
}

Indications and Complications at Teaching Hospital, Faisalabad

Dr. Nazia Mussarat, Dr. Saima Qurashi, Prof. Dr. Mahnaz Roohi

ABSTRACT... Introduction: Caesarean section is one of the commonly performed surgical procedures in obstetric and is certainly one of the oldest operations in surgery. Recently there has been a dramatic rise in the caesarean section rate world wide especially in the developed countries. As primary caesarean deliveries contributed most to the overall caesarean section rate (CSR). So this is clear that primary caesarean section is an important target for reduction because it leads to an increased risk for repeat caesarean delivery. Objectives: To have an overview of fetomaternal indications for LSCS at a teaching hospital And to review intra-operative and postoperative complications of LSCS at tertiary care centre. Material And Methods: All caesarean sections performed at Obstetrics and Gynecology Unit Independent University Hospital Faisalabad from January 2009 to December 2010 were reviewed. Information was obtained from operation theater and labor ward records. Results: During the study period 100 patients undergone caesarean section. Out of 100 patients, $58(58 \%)$ had emergency and $42(42 \%)$ had elective caesarean section. The leading maternal indications were previous caesarean section $34(34 \%)$, severe pre- eclampsia $6(6 \%)$,post date\& failed induction of labor6 $(6 \%)$, placenta previa $6(6 \%)$, and failure of progression of labor 5(5\%), PROM3(3\%), Pre-PROM3(3\%)and cephalopelvic disproportion2 (2\%). Major fetal indications include fetal distress9 (9\%), malpresentation 6(6\%), cord prolapse 3(3\%),IUGR 5(5\%) and pregnancy complicated by multiple fetuses $7(7 \%)$. Intraoperative surgical and anesthetic complications were observed in very few patients. Nine babies had perinatal deaths in this study, 8 belonged to emergency and only one baby died in elective group due to aspiration pneumonia. Conclusions: Majority of cesarean section are done in emergency situations and previous CS is the most frequent indication of cesarean section. The most effective mean to control CS is the prevention of first caesarean section which could be achieved by adopting the policy of trial of vaginal birth after previous Csection, selective vaginal breech delivery and regular audit of $\mathrm{C}$-section as well as early detection of at risk cases and proper referral in time is the key factor in decreasing the cesarean section rate and complications.

Key words: Caesarean section, indications, C-section complications

Article Citation

Mussart N, Qureshi S, Roohi M. Lower segment cesarean section (LSCS); indications and complications at teahcing hospital, Faisalabad. Professional Med J 2013;20(6): 916-923.

\section{INTRODUCTION}

Caesarean section is one of the commonly performed surgical procedures in obstetric and is certainly one of the oldest operations in surgery ${ }^{1}$.

There are two types of Caesarean section (CS). An important distinction lies in the type of incision made on the uterus, apart from the incision on the skin. According to type of incision, these two types includes the classical Caesarean section (CS) and lower uterine segment section (LSCS). The classical Caesarean section involves a longitudinal incision in upper uterine segment which allows a larger space to deliver the baby. However, it is rarely performed today, as it is more prone to complications. The lower uterine segment section is the procedure most commonly used today; it involves a transverse cut just above the edge of the bladder and results in less blood loss and is easier to repair. It may be transverse (the usual) or vertical in the different conditions that involves presence of lateral varicosities, constriction ring to cut through it and deeply engaged head ${ }^{2}$.

Recently there has been a dramatic rise in the caesarean section rate worldwide especially in the developed countries. The reasons for this increase in caesarean birth are multifactorial and include the increasing number of women with prior caesarean delivery, the increase in multifetal gestations, use of intrapartum electronic fetal monitoring, changes in obstetric training, medico legal concerns, alterations in parental and social expectations of pregnancy outcome and maternal autonomy in decision - making regarding delivery mode ${ }^{3}$. Over the last century 
delivery by caesarean section has become increasingly safer but it can not replace vaginal delivery in terms of low maternal and neonatal morbidity and less cost ${ }^{4}$.

Women are now four times more likely to have caesarean birth than 30 years ago. Many programmes have been developed to reduce the rate of caesarean delivery ${ }^{5}$.

Approximately one third of caesarean sections are performed electively and two third are performed as emergency procedures. Primary caesarean sections have a major contribution in determining the future obstetric course of a woman. Among the primary caesarean deliveries the most common indication for an elective procedure is breech presentation and for an emergency procedure includes labour dystocia and non- reassuring fetal heart rate tracings ${ }^{6}$.

As primary caesarean deliveries contributed most to the overall caesarean section rate (CSR). Wide variation in clinical practice among the obstetricians was identified. Main factor for these inconsistencies in clinical practice was attributed to the lack of adherence to standard guidelines and lack of acceptable benchmarks for the rates of caesarean section, induction of labour and failed inductions. Induced cases contributed most to primary caesarean sections. Too many inductions on vague indications and poor bishop scores, assessment and decision making by junior doctors, and missing partograms were observed as a frequent occurrence.

Considering the indications for caesarean section the repeat caesarean section, labour dystocia, fetal distress, APH etc are commonly reported in Pakistan.

Repeat caesarean section accounted for the largest proportion of caesarean deliveries in United Kingdom ${ }^{8}$.

So this is clear that primary caesarean section is an important target for reduction because it leads to an increased risk for repeat caesarean delivery ${ }^{9}$.

There is a wide variation in trends of indications and rate of caesarean section. In recent years the rate has increased to a record level of $46 \%$ in China and $25 \%$ and above in many Asian countries, Latin America and the USA ${ }^{10}$.

Caesarean associated maternal and fetal morbidity and mortality has been brought down during this century due to improved operative technique and facilities. But with emergency procedure risk of maternal and fetal morbidity and mortality increases many folds and efforts must be made to reduce the incidence and complications of emergency Caesarean section.

This study was conducted to analyze the indications and complications of caesarean sections in terms of patient's social and clinical characteristics so as to find out reasons for increased caesarean delivery and to reduce complications. As cesarean section in primi gravidas have adverse consequences in forthcoming pregnancies.

\section{Objectives}

The objectives of our study are:

1. To have an overview of fetomaternal indications for LSCS at a teaching hospital.

2. To review intra-operative and post-operative complications of LSCS at tertiary care centre.

\section{Study Design}

A retrospective study

Study Period

From January 2009 to December 2010

\section{MATERIAL AND METHODS}

All caesarean sections performed at Obstetrics and Gynecology Unit Independent University Hospital 
Faisalabad from January 2009 to December 2010 were reviewed. Information was obtained from operation theater and labor ward records. The patient's evaluation was done on designed performed. Data were collected regarding the age, parity, indications, perinatal outcome and the type of caesarean section (emergency or elective). The indications were classified as maternal and fetal.

All the patients who underwent caesarean section were analyzed in terms of socio-demographic data as well as for indications of CS. It included all the pregnant ladies booked, un-booked and referred cases admitted either through emergency or OPD.

According to urgency of CS they were grouped as emergency or elective caesarean cases. Collected data was entered in the SPSS statistical package for analysis. Preterm babies or babies with poor APGAR score were shifted to NNU and were managed by pediatric department. All these contributed to decreased fetal morbidity and mortality.

\section{RESULTS}

During the study period 100 patients were undergone caesarean section. Out of 100 patients, 58(58\%) had emergency and $42(42 \%)$ had elective caesarean section(Figure №!).

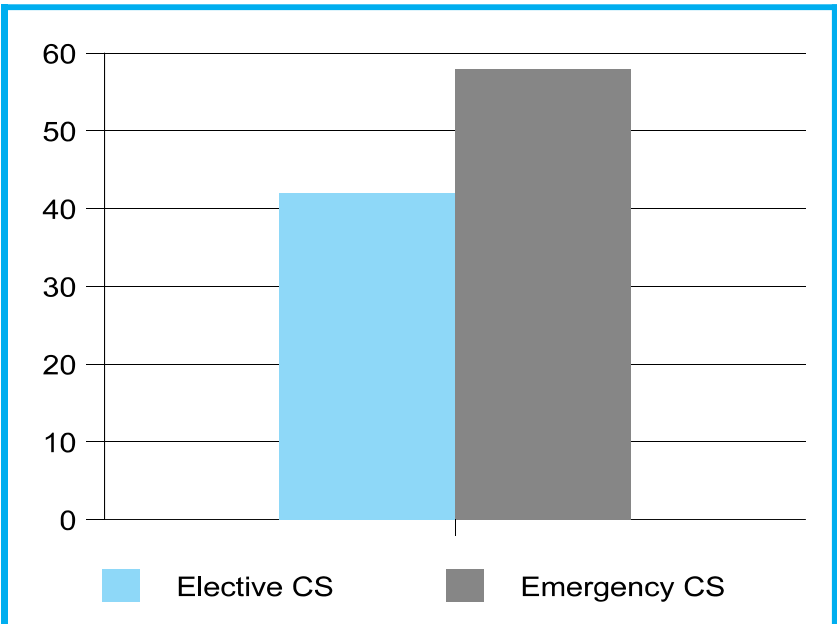

Figure-1. Ratio of emergency and elective CS
The age of the patients ranged between 18 and 36 years with a mean age of 27.45 years. Most of the patients $(80 \%)$ were in $20-30$ years age group. Youngest was 18 years of age and eldest was of 36 years. $86 \%$ cases were below 30 years of age while only $16 \%$ were of more than 30 year(Figure no 2 ).

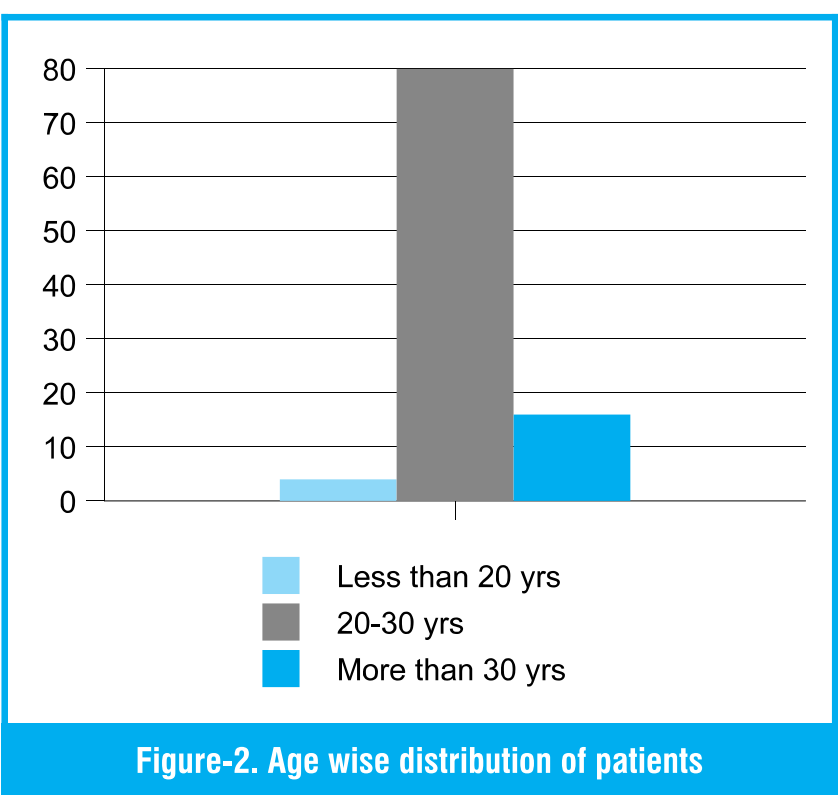

Table-I showed the indications for the caesarean sections in this study. The leading maternal indications were previous caesarean section $34(34 \%)$, severe pre- eclampsia $6(6 \%)$,post date\& failed induction of labor $6(6 \%)$, placenta previa $6(6 \%)$, and failure of progression of labor $5(5 \%)$, PROM3(3\%), PrePROM3(3\%)and cephalopelvic disproportion2 (2\%).

Major fetal indications include fetal distress9 $(9 \%)$, malpresentation $6(6 \%)$, ,cord prolapse 3(3\%),IUGR $5(5 \%)$ and pregnancy complicated by multiple fetuses $7(7 \%)$.

Miscellaneous indication includes fibroid(1\%), precious pregnancy $(1 \%)$, chorioamnionitis (1\%), cervical dystocia(1\%), and $\mathrm{PIH}(1 \%)$.

32 were primigravidae while 78 were multigravida. The range of gravidity is shown in figure no 3 . 
Intra-operative surgical and anesthetic complications were observed in very few patients. Thirteen out of 100 patients got surgical complications, out of whom 10 were from emergency caesarean section $(90 \%)$ and only three was from elective group (10\%). Amongst these complications, difficult endotracheal intubation was the most common problem encountered. Six patients out of 13 faced this problem

\begin{tabular}{|c|c|c|}
\hline Name of indications & No. of patients & \%age of pts. \\
\hline Previous C/S & 34 & $34 \%$ \\
\hline Fetal distress & 9 & $9 \%$ \\
\hline Twin & 7 & $7 \%$ \\
\hline Malpresentation & 6 & $6 \%$ \\
\hline $\begin{array}{l}\text { Post date \& failed } \\
\text { induction }\end{array}$ & 6 & $6 \%$ \\
\hline Severe pre-eclampsia & 6 & $6 \%$ \\
\hline Placenta previa & 5 & $5 \%$ \\
\hline IUGR & 5 & $5 \%$ \\
\hline $\begin{array}{l}\text { Failure to progress of } \\
\text { labor }\end{array}$ & 5 & $5 \%$ \\
\hline PROM & 3 & $3 \%$ \\
\hline $\begin{array}{l}\text { Cord presentation / } \\
\text { prolapse }\end{array}$ & 3 & $3 \%$ \\
\hline Pre-PROM & 3 & $3 \%$ \\
\hline CPD & 2 & $2 \%$ \\
\hline Fibroid & 1 & $1 \%$ \\
\hline Chorioaminiotis & 1 & $1 \%$ \\
\hline $\mathrm{APH}$ & 1 & $1 \%$ \\
\hline Precious pregnancy & 1 & $1 \%$ \\
\hline $\mathrm{PIH}$ & 1 & $1 \%$ \\
\hline Cervical dystochia & 1 & $1 \%$ \\
\hline Total no. of patients & 100 & $100 \%$ \\
\hline
\end{tabular}

and 5 were belonging to emergency group. Hemorrhage occurred in 3\% patients. Extension of uterine incision/tear, bladder injury and caesarean hysterectomy complicated only emergency group as shown in Table-ll.

\begin{tabular}{|l|c|c|}
\hline \multicolumn{1}{|c|}{ Name of complication } & $\begin{array}{c}\text { No. of } \\
\text { patients }\end{array}$ & $\begin{array}{c}\text { \%age of } \\
\text { patients }\end{array}$ \\
\hline $\begin{array}{l}\text { Difficult endotracheal } \\
\text { intubation }\end{array}$ & 6 & $6 \%$ \\
\hline Hemorrhage & 3 & $3 \%$ \\
\hline $\begin{array}{l}\text { Extension of uterine } \\
\text { incision/tear }\end{array}$ & 2 & $2 \%$ \\
\hline Bladder injury & 1 & $1 \%$ \\
\hline Caesarean hysterectomy & 1 & $1 \%$ \\
\hline Total & 13 & $13 \%$ \\
\hline \multicolumn{2}{|l|}{ Table-II. Intra operative maternal complications } \\
\end{tabular}

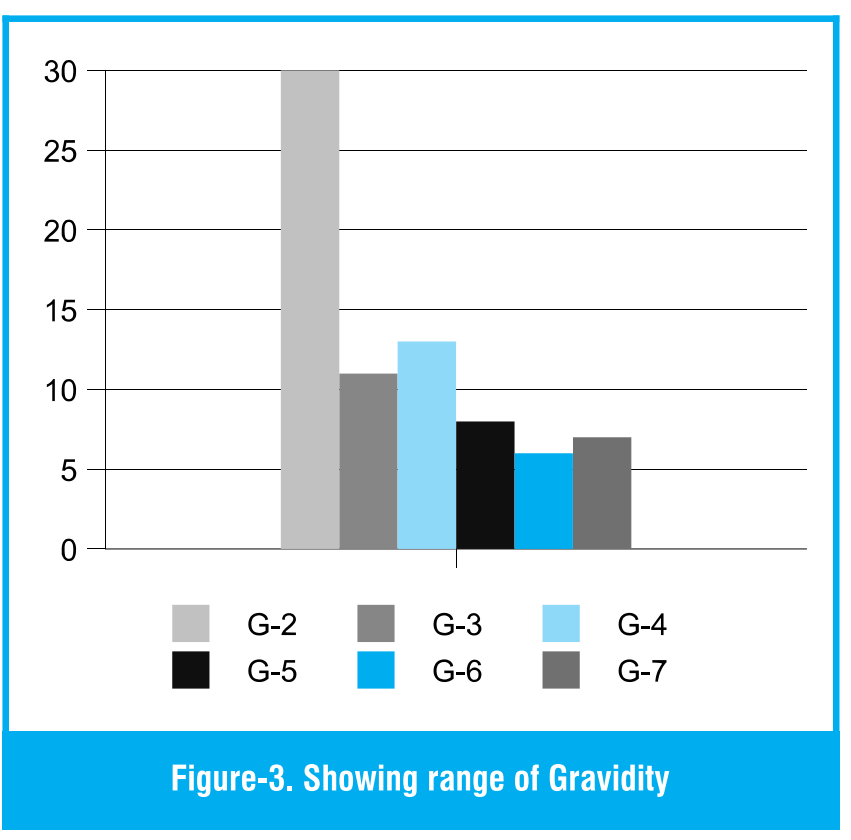

Table-III shows that urinary tract infection $19(19 \%)$ and spinal headache $10(10 \%)$ was the commonest complication encountered following caesarean section. UTI was the commonest complication encountered in elective group and the reason might be 
the indwelling catheter. Other common complications faced were wound infection, pelvic and genital tract infection, chestinfections (Table-III).

\begin{tabular}{|l|c|c|}
\hline \multicolumn{1}{|c|}{ Name of complication } & $\begin{array}{c}\text { No. of } \\
\text { patients }\end{array}$ & $\begin{array}{c}\text { \%age of } \\
\text { patients }\end{array}$ \\
\hline Spinal headache & 10 & $10 \%$ \\
\hline Urinary tract infection & 19 & $19 \%$ \\
\hline Chest infection & 4 & $4 \%$ \\
\hline Wound infection & 4 & $4 \%$ \\
\hline Pelvic \& genital infection & 1 & $1 \%$ \\
\hline Total & 38 & $38 \%$ \\
\hline
\end{tabular}

Table-III. Post operative maternal complications

Nine babies have perinatal deaths in this study, 8 belonged to emergency and only one baby died in elective group due to aspiration pneumonia.Four babies have congenital malformations while aspiration of meconium occurred in $3 \%$ neonates. Respiratory distress sundrome was found in 3 babies, 2 were belonging to emergency group and one to elective group. Overall perinatal morbidity was higher in emergency group. (Table-IV).

\begin{tabular}{|l|c|c|}
\hline \multicolumn{1}{|c|}{ Name of complication } & $\begin{array}{c}\text { No. of } \\
\text { patients }\end{array}$ & $\begin{array}{c}\text { \%age of } \\
\text { patients }\end{array}$ \\
\hline Perinatal death & 9 & $9 \%$ \\
\hline Congenital malformation & 4 & $4 \%$ \\
\hline Aspiration of meconium & 3 & $3 \%$ \\
\hline Respiratory distress & 3 & $3 \%$ \\
\hline Total & 19 & $19 \%$ \\
\hline \multicolumn{2}{r|}{ Table-IV. Fetal complications } \\
\hline
\end{tabular}

\section{DISCUSSION}

Cesarean section is one of the oldest operations performed. In the past it was usually performed for maternal reasons but nowadays frequently performed for fetal reasons in addition to maternal reasons. Many obstetricians prefer it mainly because of fear of Litigation. Being a major surgical intervention it is associated with significant immediate and delayed maternal morbidity and mortality.

The frequency of caesarean section depends on the inherent characteristics of the obstetrics population, socio-demographic pattern, referral role of the hospital, departmental policies regarding management of cases of dystocia, breech, fetal distress and previous caesarean section, physician factor, medico-legal aspects and consideration of maternal choice and wishes.

in this study the leading maternal indications were previous caesarean section (34\%), severe preeclampsia (6\%),post date\& failed induction of labor $(6 \%)$, placenta previa $(6 \%)$, and failure of progression of labour (5\%)PROM(3\%), Pre-PROM(3\%)and cephalopelvic disproportion (2\%).

Independent University Hospital is a tertiary care hospital of the city dealing with large number of referred cases and providing obstetric care at low cost. This is one of the important reasons for increasing number of repeated caesarean sections in our department.

Messaoudi $\mathrm{F}$ et al reported scarred uterus constitutes the dominant indication $(34 \%)$ followed by fetal suffering (24.7\%), failure of trial of labor (14.2\%) and breech presentation (12.7\%), a finding, partly correlates and partly does not correlate with our findings ${ }^{11}$.

In this study the commonest indication was repeat CS in $34(34 \%)$ cases. Our results are similar to other studies conducted by Belgrave $S$ and Sheikh L et al ${ }^{12}$.

According to Bragg $\mathrm{F}$ et al and RCOG guidelines, the likelihood of a caesarean section is strongly associated with maternal characteristics and clinical risk factors. Women were more likely to have 
caesarean section if they had a previous caesarean section (71\%), if baby is breech (90\%) or if the women had APH (85\%). It is therefore important to pay attention to the first labour as its outcome greatly determines the future mode of delivery ${ }^{13}$.

Similar correlations were noted in this study. Similarly Repeat CS accounted for the largest proportion of CS in the UK, while mother who achieved a vaginal delivery in their first pregnancy are very unlikely to end up with a CS in subsequent deliveries ${ }^{14}$.

It is therefore important to pay attention to the first labour as its outcome greatly determines the future mode of delivery ${ }^{13}$.

As Primary caesarean section usually determines the future obstetric course of any woman and therefore should be avoided wherever possible. The 1-2\% risk of scar dehiscence associated with trial of vaginal birth after caesarean section (VBAC) can result in serious maternal and perinatal morbidity and mortality in subsequent pregnancies.

Kenner $\mathrm{R}$ et al have found that women who had just one previous caesarean section were more likely to have problems with their second birth, including increased risk of malpresentations, $\mathrm{APH}$, placenta previa, placenta accreta, prolonged labour, risk of scar dehiscence, uterine rupture, preterm birth etc. They concluded that some risks may be due to confounding factors related to the indications for the first CS rather than procedure itself ${ }^{15}$.

Silver RM et al also reported that Women who had multiple CS were more likely to have problems with later pregnancies like placenta accreta ${ }^{16}$. WHO estimates the rate of CS between $10 \%-15 \%$ of all births in developed countries ${ }^{17}$.

A study conducted in Singapore General Hospital, comparing two times period in 1998 and 2001 has shown that increase in cesarean section rate in 2001 was attributed to statistically significant increase in cesarean section for previous cesarean section and placenta previa major ${ }^{18}$.

In our study major fetal indications include fetal distress (9\%), malpresentation (6\%), ,cord prolapse (3\%),IUGR (5\%) and pregnancy complicated by multiple fetuses.

Similar findings reported by Lubna Ali Karachi and Shamshad Abbottabad found obstructed labor and fetal distress were the second and third common causes of c-section $^{19,20}$.

Florica M etal from Sweden reported suspected fetal distress $(+1.6, p=0.001)$ maternal request $(+1.5 \%$, $p<0.0001)$ and labor dystocia $(+0.8 \%, p=0.03)$ were associated with the increase in caesarean section rates, findings which does not correlate with ourfindings ${ }^{21}$.

While Haverkemp and colleagues have shown a higher cesarean section rate for fetal distress, when the use of continuous electronic fetal monitoring is compared with intermittent auscultation of fetal heart ${ }^{22}$.

All types of maternal and Fetal complications are seen more commonly with emergency cases as compared to elective one. But maternal and fetal morbidity and mortality is largely dependent on the nature of the condition for which the operation was performed.

Similarly Neilson et al showed that intra operative caesarean section complications rate was higher In emergency as compared to elective section ${ }^{23}$.

Postoperative complications rate was also more frequent in emergency. Spinal headache was having nearly same frequency in said groups. 
A point about data collection on caesarean section is that not only is the number of caesarean section performed important, but also, crucially, weather they have been performed on the right women at the right time and in an acceptable manner. Accurate collection of data on caesarean sections and the indications has to be continually emphasized. The aim should not be to worry weather the caesarean section rate is too high or too low, but rather what is the rate and why? It can be considered to be appropriate, taking into consideration all the relevant outcome factors. The decrease in caesarean section rate is an important target but should never be the only target and therefore never considered in isolation.

\section{CONCLUSIONS}

The study showed that all CS performed had specific indications. Majority of cesarean section are done in emergency situations and previous CS is the most frequent indication of cesarean section. The main cause may be high prevalence of illiteracy and poverty in our female population of reproductive age, early marriages, high parity and increased maternal ages along with flaws in the health care system. The most effective mean to control previous CS is the prevention of first caesarean section which could be achieved by adopting the policy of trial of vaginal birth after previous $\mathrm{C}$-section, selective vaginal breech delivery and regular audit of $\mathrm{C}$-section as well as early detection of at risk cases and proper referral in time is the key factor in decreasing the cesarean section rate and complications.

Copyright@ 26 0ct, 2013.

\section{REFERENCES}

1. Kwawukume EY. Caesarean section. In: Kwawukume $\mathrm{EY}$, Emuveyan $\mathrm{E}$, editors. Comprehensive obstetrics in the tropic. Asante and Hittcher Printing Press Limited, 2000. p. 321-9.

2. Lower segment Caesarean section Primary Surgery: Volume One: Non-trauma. Prev. Chapter 10. The surgery of labour.
3. Mishra US, Ramanathan M. Delivery-related complications and determinants of caesarean section rates in India. Health Policy Plan 2002; 17: 908.

4. Usha Kiran TS, Jaya Wickrama NS: Who is responsible for the rising caesarean section rate? J Obstet Gynaecol 2002;22:263-365.

5. Frigoletto FD Jr, Lieberman E, Lang JM, Cohen A, Barss $\mathrm{V}$, Ringer $\mathrm{S}$ et al. A clinical trial of active management of labor. N Eng J Med 1995; 333: 745-50.

6. Belgrave S. Caesarean Section. N Z Fam Physic 2003:30:269-72.

7. Gulfareen H, Nishat Z, Aftab AM, Ambreen H. Pak J Med Sci 2009; 25:786-91.

8. Royal College of Obstetricians and Gynaecologists. Birth after previous caesarean section. Green top guidelines no.45. London (UK) RCOG Press. 2007.

9. Robson MS. Can we reduce the caesarean section rate? Best Pract Res Clin Obstet Gynaecol 2001; 15:179-94

10. World Health Organization. Appropriate technology for birth ih . L a n c et 1985;2(8452):436-7.

11. Messaoudi $\mathrm{F}$ et al: Caesarean deliveries in the maternity of military hospital of Tunis. Tunis Med 2007 Aug 85(8):659.

12. Sheikh L, Tehseen S, Gowani SA, Bhurgri H, Rizvi JH, Kagazwala $S$. Reducing the rate of primary caesarean section - an audit. J Pak Med Assoc 2008; 58:444-8.

13. Bragg F, Cromwell DA, Edozien LC, Gurol- Unganci I, Mahmood TA, Templeton A, et al. Variation of caesarean section among English NHS trusts after accounting for maternal and clinical risk: cross sectional study. Br Med J 2010;341:c5065.

14. Robson MS. Classification of caesarean section. Fetal Maternal Med Rev 2001; 12:23-39.

15. Kennare R, Tucker G, Heard A, Chan A. Risks of adverse outcomes in the next birth after a first caesarean delivery. Obstet Gynaecol 2007;109:2706. 
16. Silver RM, Landon MB, Rouse DJ, Leveno KJ, Spong $\mathrm{CY}$, Thom EA, et al. Maternal morbidity associated with multiple repeat caesarean deliveries. Obstet Gynaecol 2006;107:1226-32.

17. World Health Organization. Appropriate technology for birth. La a c et 1985;2(8452):436-7.

18. Tan WC, Devendra K, Tan AS. Changing trends in indications for caesaren sections in a tertiary hospital. Ann Acad Med Singapore 2003; 32: 299304.

19. Shamshad. Factors leading to increased caesarean section rate. Gomal J Med Sci 2008;vol 6, no 1, page $1-5$.
20. Lubna Ali, Subhana Tayyab, Fouzia Perveen. Ceasarean c-section rate: current trends. J Surg Pakjun 2007; 12(2):64-6.

21. Florica M, Stephansson 0, Nordstöm L: Indications associated with increased caesarean section rates in a Swedish hospital. Int J Gynaecol Obstet 2006 Feb 92(2):181-5.

22. Haverkamp AD, Thompson HE, Mcfee JG. The evaluation of continuous fetal heart rate monitoring in the high risk pregnancy. Am J Obstst Gynaecol 1976; 125:310-20.

23. Neilsen TF. Caesarean section. A controversial features of modem obstetric practice. Obstet Gynaecol 1986; 21:57.

\section{AUTHOR(S):}

1. DR. NAZIA MUSSARAT

MBBS, FCPS

Assistant Professor

Department of Obs. \& Gynae.

Independent Medical College, Faisalabad

2. DR. SAIMA QURASHI

MBBS, FCPS

Assistant Professor

Department of Obs. \& Gynae.

Independent Medical College, Faisalabad

3. PROF. DR. MAHNAZ ROOHI

MBBS, FRC-OG

Head Department of Obs. \& Gynae.

Independent Medical College, Faisalabad

\section{Correspondence Address:}

Dr. Nazia Mussarat

MBBS, FCPS

Assistant Professor

Department of Obs. \& Gynae.

Independent Medical College, Faisalabad

doctorfaheem2000@yahoo.com

\section{Our character is what we do when we think no one is looking.}

